\title{
Microstructural changes induced by low energy heavy ion irradiation in titanium silicon carbide
}

Authors

J.C. Nappéa ${ }^{a \dagger}$ C. Maurice ${ }^{b}$, Ph. Grosseau ${ }^{a}$, F. Audubert ${ }^{c}$, L. Thoméd, B. Guilhot ${ }^{e}$, M. Beauvyc ${ }^{c}$, M. Benabdesselam ${ }^{f}$

a École Nationale Supérieure des Mines, SPIN/PMMC, LPMG UMR CNRS 5148, 158 cours Fauriel, 42023 Saint-

Étienne cedex 2, France

${ }^{\mathrm{b}}$ École Nationale Supérieure des Mines, SMS/MPM, PECM UMR CNRS 5146, 158 cours Fauriel, 42023 Saint-Étienne cedex 2, France

${ }^{\mathrm{c}}$ CEA, DEN, DEC/SPUA/LTEC, Cadarache, 13108 St Paul lez Durance, France

${ }^{d}$ Centre de Spectrométrie Nucléaire et de Spectrométrie de Masse, CNRS-IN2P3-Université Paris Sud, Bât. 108, 91405

Orsay, France

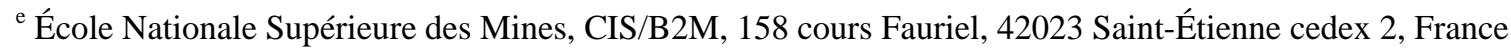

${ }^{\mathrm{f}}$ Université de Nice - Sophia Antipolis, LPMC UMR CNRS 6622, Parc Valrose, 06108 Nice cedex 2, France

\section{ABSTRACT}

Low energy ion irradiation was used to investigate the microstructural modifications induced in $\mathrm{Ti}_{3} \mathrm{SiC}_{2}$ by nuclear collisions. Characterization of the microstructure of the pristine sample by electron back-scatter diffraction (EBSD) shows a strong texturing of $\mathrm{TiSi}_{2}$, which is a common secondary phase present in $\mathrm{Ti}_{3} \mathrm{SiC}_{2}$. A methodology based on atomic force microscopy (AFM) was developed to measure the volume swelling induced by ion irradiation, and it was validated on irradiated silicon carbide. The swelling of $\mathrm{Ti}_{3} \mathrm{SiC}_{2}$ was estimated to $2.2 \pm 0.8 \%$ for an irradiation dose of 4.3 dpa at room temperature. Results obtained by both EBSD and AFM analyzes showed that nuclear collisions induce an anisotropic swelling in $\mathrm{Ti}_{3} \mathrm{SiC}_{2}$.

Keywords: $\mathrm{Ti}_{3} \mathrm{SiC}_{2}$, nuclear interaction, electron back-scatter diffraction, atomic force microscopy, anisotropic swelling

PACS: 81.05.Je, 61.80.Lj, 25.75.Ag, 28.41.Bm, 68.37.Ps, 61.05.J-

\section{Introduction}

The Gas-cooled Fast Reactor (GFR) is one of six new systems studied in the framework of the Generation IV International Forum (GIF). These systems are characterized by an increased security level, a better economic competitiveness, and the ability to recycle all the fuel in order to upgrade it to a fissionable material and to minimize long-lived waste production by transmutation [1]. The GFR is designed to work under helium-pressure and at hightemperature (1100-1300 K). Due to these working conditions, non-oxide refractory ceramics are required as fuel cladding. Thus, carbides turn out to be excellent candidates due to their remarkable mechanical and thermal properties. However, their behavior under irradiation has to be investigated.

Among potential carbides, ternary $\mathrm{Ti}_{3} \mathrm{SiC}_{2}$ presents some interesting properties. In 1972 Nickl et al. [2] remarked that this material is abnormally soft for a carbide, so that its hardness decreases as the applied load increases. For this reason Goto et al. [3] qualified $\mathrm{Ti}_{3} \mathrm{SiC}_{2}$ as a "ductile ceramic". Furthermore, $\mathrm{Ti}_{3} \mathrm{SiC}_{2}$ combines the properties of metals with those usually attributed to ceramics [4-7]. Thus, this material is not only soft but also stiff and tough, it behaves as a good electrical and thermal conductor, and it can be easily machined with the tools generally used for steels.

$\dagger \quad$ Corresponding author. Tel.: +33 477420 213; fax: +33 477499694.

E-mail address: jc.nappe@yahoo.fr (JC. Nappé). 
The interesting mechanical properties of $\mathrm{Ti}_{3} \mathrm{SiC}_{2}$ suggest that this compound could be used as fuel cladding material. Its damage tolerance to mechanical stresses might indicate a high resistance to irradiation. Nevertheless, apart from few recently published articles related to $\mathrm{Ti}_{3} \mathrm{SiC}_{2}$ [8-10], and $\mathrm{Ti}_{3}(\mathrm{Si}, \mathrm{Al}) \mathrm{C}_{2}$ [11-14], few information is available about its behavior under irradiation.

Previously [15,16], we showed that an irradiation performed at room temperature with $4 \mathrm{MeV} \mathrm{Au}$ ions to a fluence of $10^{19} \mathrm{~m}^{-2}$ induces both an erosion of the $\mathrm{Ti}_{3} \mathrm{SiC}_{2}$ grain boundaries, as observed by scanning electron microscopy, and a revealing of the grain structure, as evidenced by atomic force microscopy. We attributed the former phenomenon to a preferential sputtering due to lower threshold displacement energy of the atoms located in grain boundaries. For the latter result, we were led to consider the occurrence of preferential sputtering as a function of the crystallite orientation. In this work, complementary irradiation experiments suggest another explanation.

\section{Experimental}

The polycrystalline samples were provided by the 3-ONE-2 company (Vorhees, NJ, USA). They consist of about $74 \%$ $\mathrm{Ti}_{3} \mathrm{SiC}_{2}, 19 \% \mathrm{TiC}_{0.92}$, and $7 \% \mathrm{TiSi}_{2}$ (as estimated by X-ray diffraction). As-received samples were polished with diamond paste of a size down to 1 micron.

The interactions occurring in reactors are essentially elastic (or nuclear) collisions due to primary knock-on atoms from neutrons, and recoil atoms arising from alpha-decays. In order to simulate these interactions, low energy ion irradiations are usually performed. Thus, the polished face of the samples was irradiated with $4 \mathrm{MeV} \mathrm{Au}$ ions provided by the ARAMIS accelerator (CSNSM-Orsay, France). Table 1 summarizes the irradiation conditions.

Table 1: Irradiation conditions.

\begin{tabular}{l|lll}
\hline Temperature & Room Temperature & $773 \mathrm{~K}$ & $1223 \mathrm{~K}$ \\
\hline Fluence $\left(\mathrm{m}^{-2}\right)$ & $10^{16}, 10^{17}, 10^{18}, 10^{19}$ & $10^{16}, 10^{17}, 10^{18}, 10^{19}$ & $10^{19}$ \\
\hline
\end{tabular}

In order to compare the results of these irradiations with previous data (especially those using neutron irradiations), it is usual to deal with the number of displacements per atoms (dpa) of the target, induced by the irradiation as a function of the depth within the irradiated material. The fluence scale has been converted into a dpa scale on the basis of TRIM2008 calculations [17], by considering the number of vacancies produced with $4 \mathrm{MeV}$ Au ions as a function of depth in $\mathrm{Ti}_{3} \mathrm{SiC}_{2}$. The displacement energies were: $25 \mathrm{eV}$ for Ti, $15 \mathrm{eV}$ for Si, and $28 \mathrm{eV}$ for C. Figure 1 shows the variation of the damage level (in dpa per fluence unit) and of the ion distribution (also estimated with the TRIM code) as a function of the depth in the target material. This Figure shows that the damaged thickness may be estimated to $760 \mathrm{~nm}$. In this layer, irradiation induces an average dpa per fluence unit of $4.3 \times 10^{-19} \mathrm{~m}^{2}$, viz. $4.3 \mathrm{dpa}$ for an irradiation to $10^{19} \mathrm{~m}^{-2}$.

Different techniques were used to characterize the surface modifications induced by ion irradiation. Atomic force microscopy (AFM) aims both to analyse the surface topography modifications and to measure the swelling. Field emission gun scanning electron microscopy (FEG-SEM) was used to underline differences between $\mathrm{Ti}_{3} \mathrm{SiC}_{2}$ and the other phases by imaging the surface of samples with back-scattered electrons. Coupled to FEG-SEM, electron backscatter diffraction (EBSD) was used to characterize the crystallites before irradiation. EBSD is a powerful technique for the quantification of both the microtexture and the microstructure of polyphased crystalline materials.

For EBSD, as-received samples were also polished with diamond suspensions down to $1 \mu \mathrm{m}$. Then, they were polished with $1 / 4 \mu \mathrm{m}$ colloidal silica suspension for 3 hours. EBSD analyzes were carried out using an HKL Technology (now Oxford Instruments) system installed on a Zeiss Supra 55 VP FEG-SEM operating at $17-20 \mathrm{kV}$ and a probe-current of about $20 \mathrm{nA}$. EBSD analyzes were not possible on irradiated samples because of the loss of crystallinity induced by nuclear collisions $[8,15]$. 


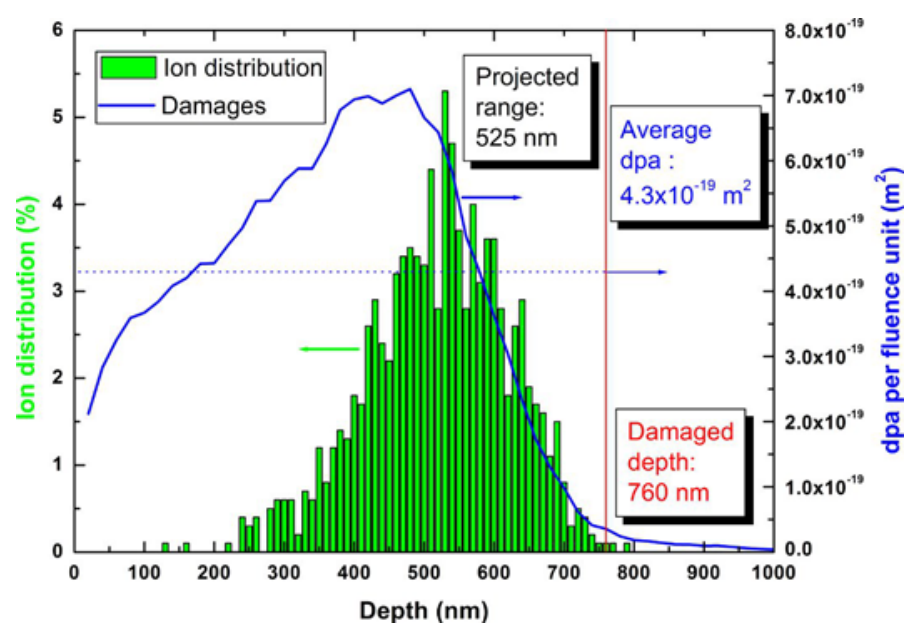

Figure 1: Depth distribution of implanted ions and number of displacements per atom (per fluence unit) for $\mathrm{Ti}_{3} \mathrm{SiC}_{2}$ irradiated with $4 \mathrm{MeV}$ Au ions.

Crystal structure data were created using the Twist add-on with the data shown in Table 2. In this $\mathrm{Table} \mathrm{Ti}_{\mathrm{I}}$ atoms correspond to the atoms of the basal planes linking the $\mathrm{CTi}_{6}$ octahedrons, and $\mathrm{Ti}_{\mathrm{II}}$ atoms to those bordering the silicon basal planes. Representations of the $\mathrm{Ti}_{3} \mathrm{SiC}_{2}$ lattice can be found elsewhere [4-6]. The complexity of the $\mathrm{Ti}_{3} \mathrm{SiC}_{2}$ diffraction patterns leads to the failure of the automatic indexation algorithm for some particular orientations. More precisely, the band recognition process using the standard Hough transform fails when Kikuchi bands are closely spaced and nearly parallel, which is the case of the $\mathrm{Ti}_{3} \mathrm{SiC}_{2}$ diffraction pattern. Nevertheless, the number of non-indexed patterns is relatively small, leading to a reliable microstructure analysis.

Table 2: Wyckoff positions of the atoms for the three phases present in the studied material.

\begin{tabular}{|c|c|c|c|c|c|c|c|}
\hline Phase & \multicolumn{4}{|c|}{$\mathrm{Ti}_{3} \mathrm{SiC}_{2}$} & \multicolumn{2}{|c|}{$\mathrm{TiC}$} & $\mathrm{TiSi}_{2}$ \\
\hline Space group & \multicolumn{4}{|c|}{$\mathrm{P}_{3} / \mathrm{mmc}(194)$} & \multicolumn{2}{|c|}{$\mathrm{Fm}-3 \mathrm{~m}(225)$} & Fddd(70) \\
\hline Atoms & $\mathrm{Ti}_{\mathrm{I}}$ & $\mathrm{Ti}_{\text {II }}$ & $\mathrm{Si}$ & C & $\mathrm{Ti}$ & $\mathrm{C}$ & $\mathrm{Ti}$ \\
\hline Wyckoff positions & $2 a$ & $4 \mathrm{f}$ & $2 b$ & $4 \mathrm{f}$ & $4 a$ & $4 \mathrm{~b}$ & $8 a \quad 16 e$ \\
\hline
\end{tabular}

\section{Results and discussion}

\subsection{Characterization of pristine samples}

The characterization of as-prepared (or pristine) samples was partly reported previously [15,16]. Briefly, we first noticed a difference in the contrast between the three phases using back-scattered electrons in the FEG-SEM. Then, by AFM we were able to distinguish TiC from the other phases due to its bigger hardness: TiC grain surfaces appear elevated above those of other phases.

In order to confirm that the microstructure revealed after irradiation at room temperature to $10^{19} \mathrm{~m}^{-2}[15,16]$ depends on the crystallite orientation, EBSD was performed on unirradiated samples. Figure 2 shows the microstructure of pristine samples as revealed by EBSD. Figure 2a corresponds to the diffraction pattern quality quantified by the "Band Contrast”, while Figure $2 \mathrm{~b}$ presents the phase distribution (with $\mathrm{Ti}_{3} \mathrm{SiC}_{2}$ in blue, $\mathrm{TiC}$ in red and $\mathrm{TiSi}_{2}$ in yellow). These mappings show distinct morphologies for the different phases: $\mathrm{Ti}_{3} \mathrm{SiC}_{2}$ appears as strongly faceted and elongated crystallites, while TiC exhibits more equiaxed shapes. The minor $\mathrm{TiSi}_{2}$ phase appears as small isolated islands, which are preferentially located near other phase grain corners. 

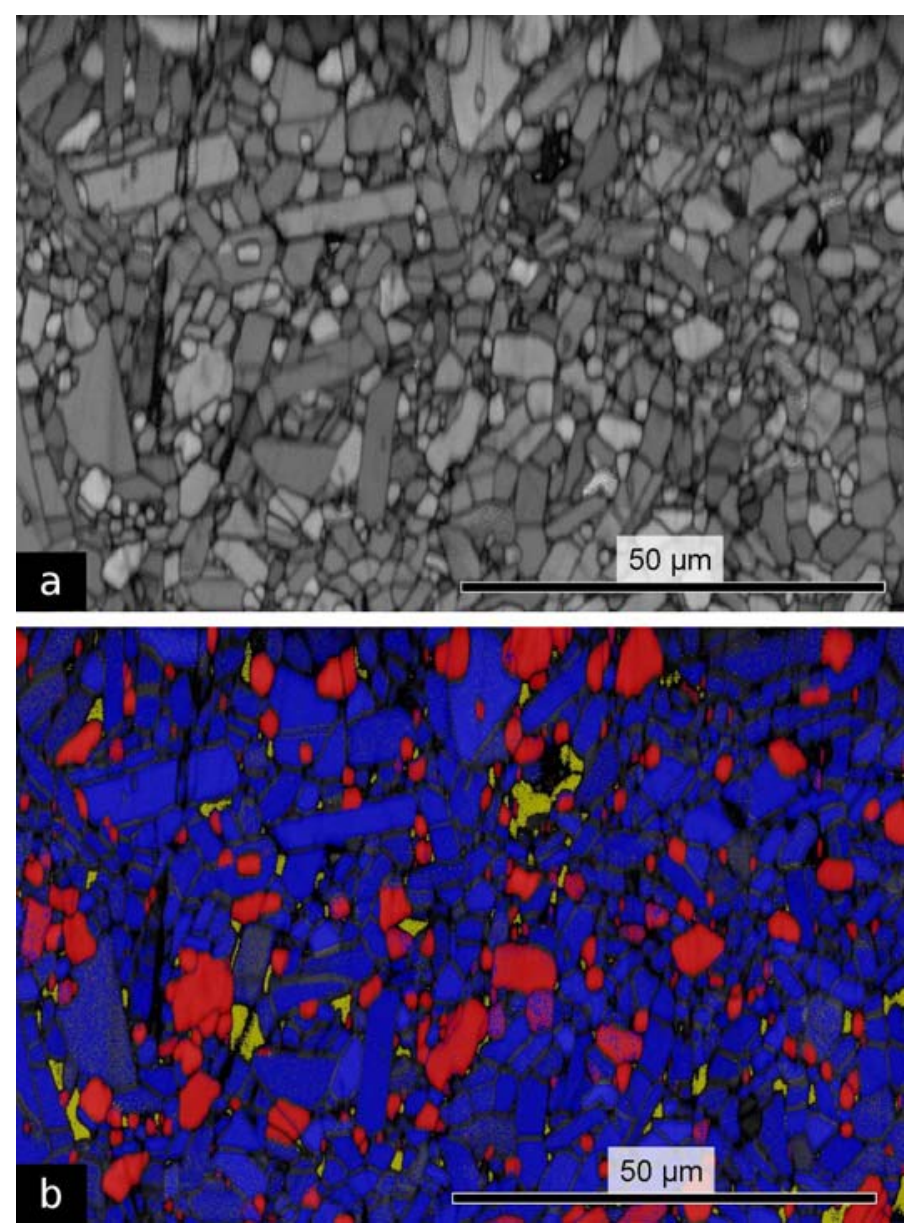

Figure 2: Microstructure of a pristine sample observed by EBSD; (a) micrograph in band contrast, (b) phase distribution: $\mathrm{Ti}_{3} \mathrm{SiC}_{2}$ in blue, $\mathrm{TiC}$ in red, and $\mathrm{TiSi}_{2}$ in yellow.

The crystallographic orientations of the different phases are shown in Figure 3. The color code corresponds to the crystallographic direction parallel to the normal direction as shown in the standard inverse pole figure for each phase. Crystallographic information can be obtained from these mappings. First, by a careful examination of the individual orientations of $\mathrm{Ti}_{3} \mathrm{SiC}_{2}$, it can be shown that the morphology of the crystallites perfectly matches the hexagonal symmetry of the crystal: the elongated and faceted crystallites (mostly green and blue on Figure 3a) have a c-axis perpendicular to the long straight edges. Other crystallites appearing in orange or red have a c-axis perpendicular to the map section and the faceted edges are perpendicular to the a-axis. From this observation, it can be concluded that this phase forms hexagonal platelets. While the most abundant phases do not have a preferential crystallographic orientation, the minor $\mathrm{TiSi}_{2}$ islands appear in the same color: this result indicates that this phase is strongly textured. This is confirmed by the pole figures of the $<100>$ directions shown in Figure 4. Other areas of the same sample have been analyzed in order to investigate this particular point. The images confirm that $\mathrm{TiSi}_{2}$ is strongly textured at a local scale.

To our knowledge, such a preferential orientation of $\mathrm{TiSi}_{2}$ has never been reported in the literature. Since this phenomenon was not observed by low-incidence X-ray diffraction [15], we believe that it is localized. Unfortunately, no explanation has yet been provided to explain such a texturing. However, two reasons may be invoked:

(i) During the synthesis of $\mathrm{Ti}_{3} \mathrm{SiC}_{2}$ a liquid eutectic $\mathrm{Si}-\mathrm{TiSi}_{2}$ could have formed at $1330{ }^{\circ} \mathrm{C}$ [18-20]; Audubert et al. [21] have shown that this liquid phase was also formed in the sintered product;

(ii) The $\mathrm{TiSi}_{2}$ phase melts at $1540{ }^{\circ} \mathrm{C}$ [22], so that as indicated by Morgiel et al. [23] it seems to wet the other grains, filling up the free spaces. 

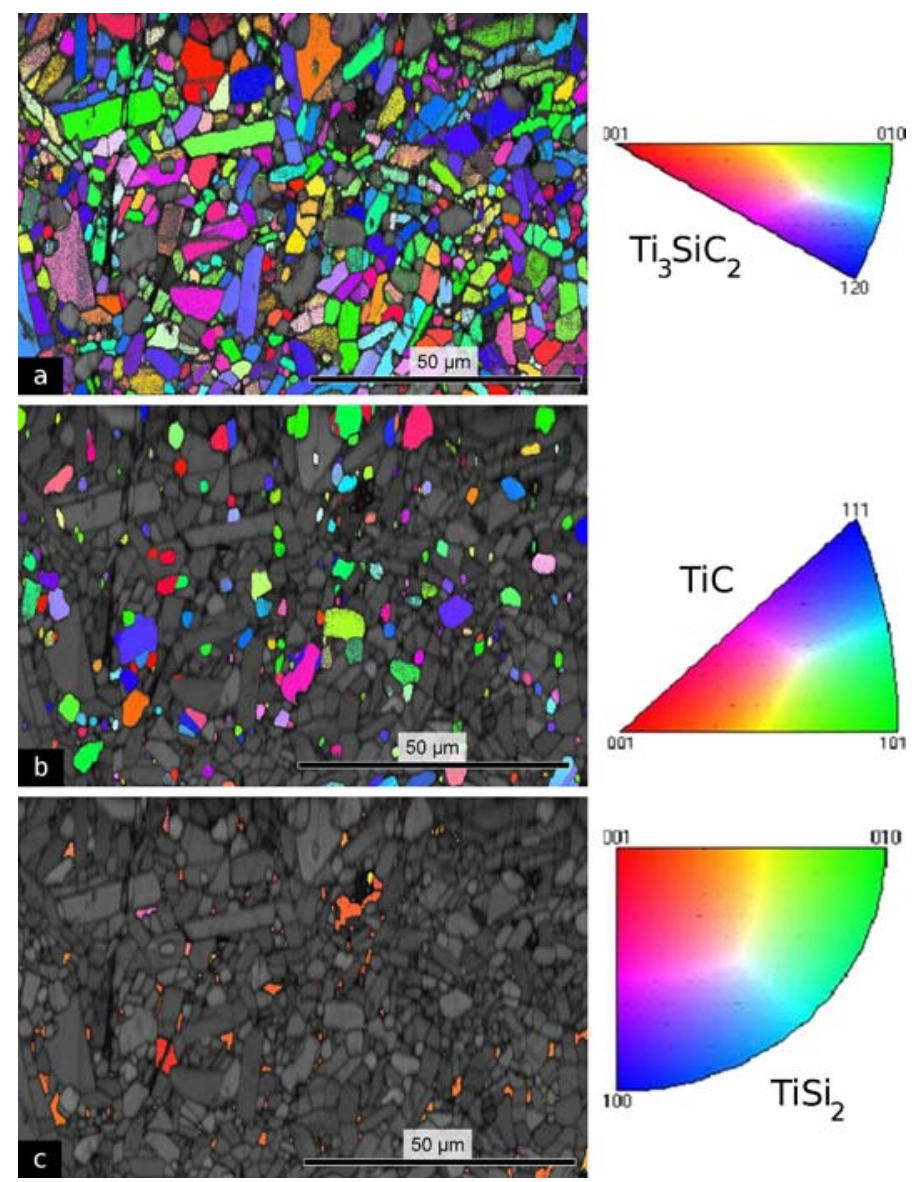

Figure 3: Mapping of the crystallographic orientation of (a) $\mathrm{Ti}_{3} \mathrm{SiC}_{2}$, (b) $\mathrm{TiC}$, and (c) $\mathrm{TiSi}_{2}$.

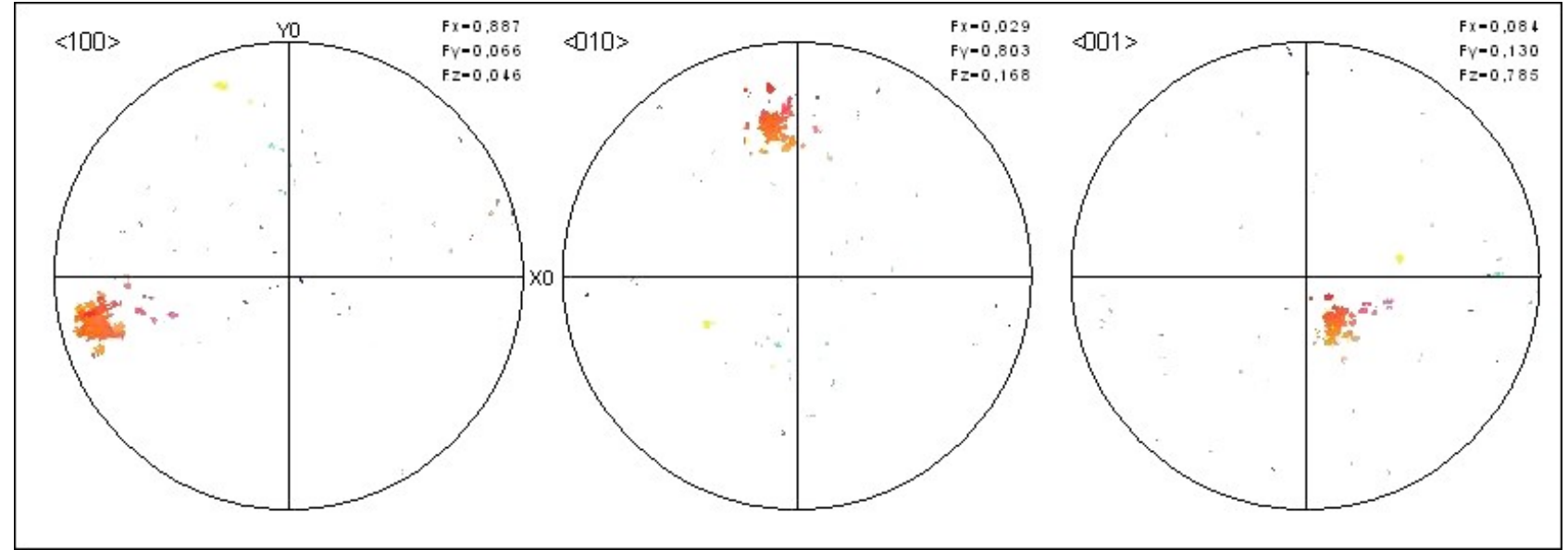

Figure 4: $<100>$ pole figures for $\mathrm{TiSi}_{2}$ showing the strong texturing of this phase on the map presented in Figure 3c.

No information is available about the sintering temperature of the studied material. However, since the sintering temperature of the $\mathrm{Ti}_{3} \mathrm{SiC}_{2}$ powder generally ranges between 1400 and $1700{ }^{\circ} \mathrm{C}$ [7,24], temperatures of 1330 and $1540{ }^{\circ} \mathrm{C}$ were probably reached during the fabrication of these samples. This feature could explain the observed preferential orientation by a liquid-solid transition. 


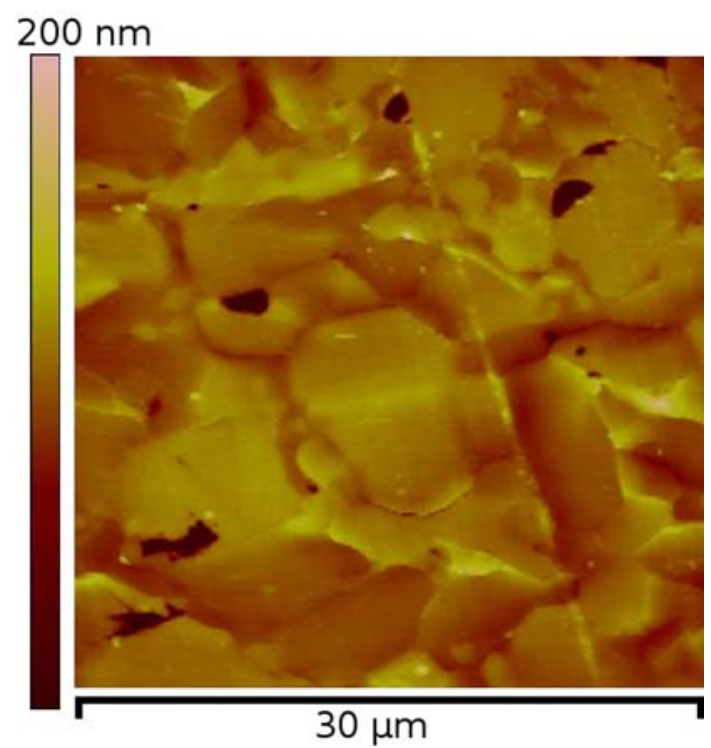

Figure 5: Microstructure revealing observed by AFM in a sample irradiated at room temperature to $10^{19} \mathrm{~m}^{-2}$.

Figure 5 shows an example of the microstructure revealing phenomenon previously observed in a sample irradiated at room temperature with $4 \mathrm{MeV}$ Au ions to $10^{19} \mathrm{~m}^{-2}$ [16]. Characterizing both the shape and the size of the revealed grains by AFM, we showed that theses grains are the same as the crystallites that may be observed by EBSD in pristine sample. This confirms that the revealing of the microstructure induced by irradiation is dependent on the crystallite orientation.

\subsection{Swelling measurements}

To measure the swelling induced by irradiation, some samples were partly irradiated by placing a protective aluminum mask on part of these samples to protect them from the ion beam. Figure 6a shows a micrograph, obtained by AFM, of the interface between the virgin and the irradiated areas for an irradiation at room temperature to $10^{19} \mathrm{~m}^{-2}$. The lighter shade of the irradiated area suggests that its height is higher than before irradiation, and therefore that irradiation has induced a swelling of the material.

Measuring the sections of partly irradiated grains on several micrographs (see Figure 6b), we estimated an average step of $16.8 \pm 6.3 \mathrm{~nm}$ between the virgin and irradiated areas for the irradiation at room temperature to $10^{19} \mathrm{~m}^{-2}$ (the large height difference between the two sections of Figure $6 \mathrm{~b}$ will be discussed later on). Since the swelling due to ion irradiation induces a change of the sample dimensions only along the ion beam direction [25-27], the measured linear swelling provides an estimation of the volume swelling. To evaluate the linear swelling, other authors compare the step induced by the irradiation either with the projected range [28] or with the damaged thickness [29] (see Figure 1). For a fluence of $10^{19} \mathrm{~m}^{-2}$, the highest fluence used in this work, the implanted-ion concentration is not large enough ( $160 \mathrm{ppm})$ to induce a significant swelling [30]. Since for lower fluences the concentration of implanted ions is less important, it appears that the projected range is not a good parameter to evaluate the volume swelling in this study. However, the observations of cross sections by transmission electron microscopy and the evaluation of lattice parameters by X-ray diffraction have highlighted that nuclear collisions induce both the formation of defects in $\mathrm{Ti}_{3} \mathrm{SiC}_{2}[8,11]$ and an increase of its unit cell volume $[8,12]$. These two phenomena provide an explanation of the swelling observed in other irradiated ceramics [27,31-33]. Thus, we decided to compare the measured step with the damaged thickness (Figure 1) to estimate the volume swelling. The results show that $\mathrm{Ti}_{3} \mathrm{SiC}_{2}$ swells by $2.2 \pm 0.8 \%$ for an irradiation dose of $4.3 \mathrm{dpa}$.

To determine whether such an estimation of the swelling induced by ion irradiation is relevant or not, we used the same methodology with a polycrystalline $\alpha$-SiC sample irradiated in the same conditions as $\mathrm{Ti}_{3} \mathrm{SiC}_{2}$ (inducing an average of $3.1 \mathrm{dpa}$ over $800 \mathrm{~nm}$ ). We estimated a swelling of $16.4 \pm 1.3 \%$ (step of $131 \pm 10 \mathrm{~nm}$ ), which is in agreement with the literature. Actually, due to its amorphization for doses higher than $0.5 \mathrm{dpa}$, the swelling of SiC would range between 10 
and $20 \%$ [29,34]. Thus, this work shows that our methodology is accurate, and that $\mathrm{Ti}_{3} \mathrm{SiC}_{2}$ swells less than $\mathrm{SiC}$ for irradiations carried out at room temperature.

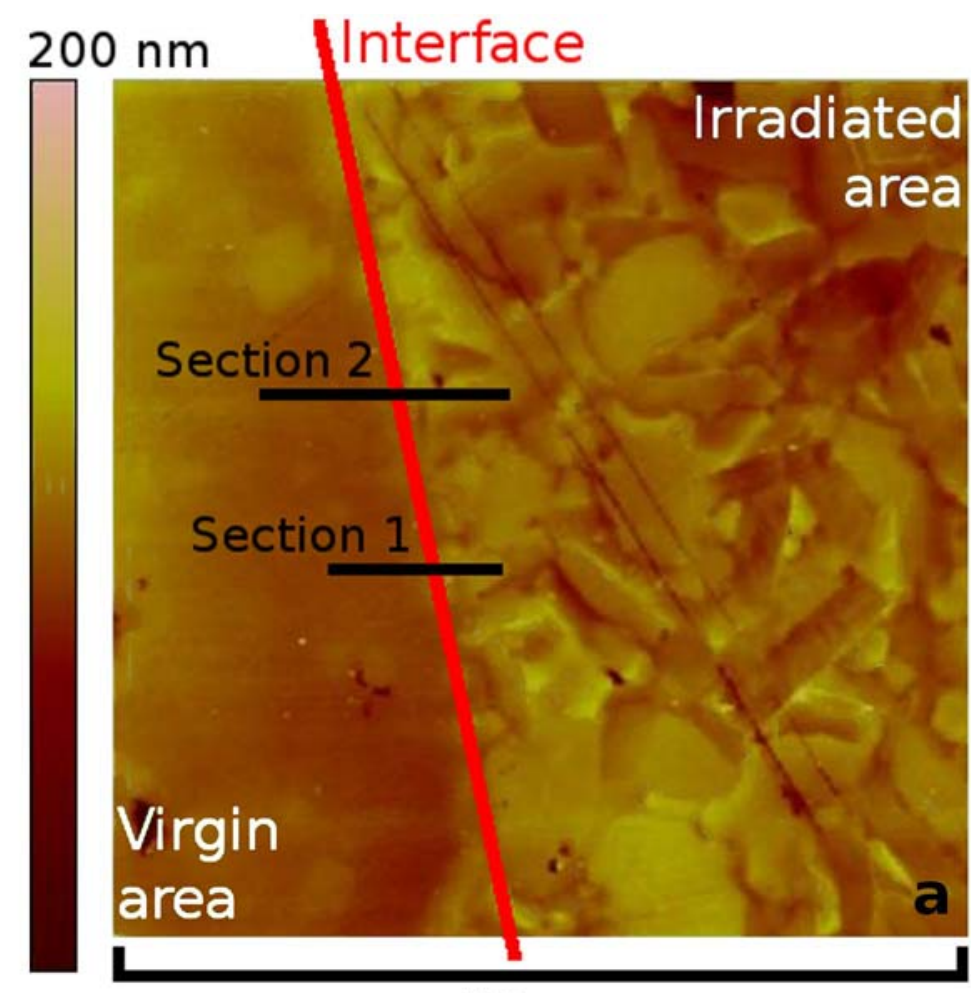

$50 \mu \mathrm{m}$

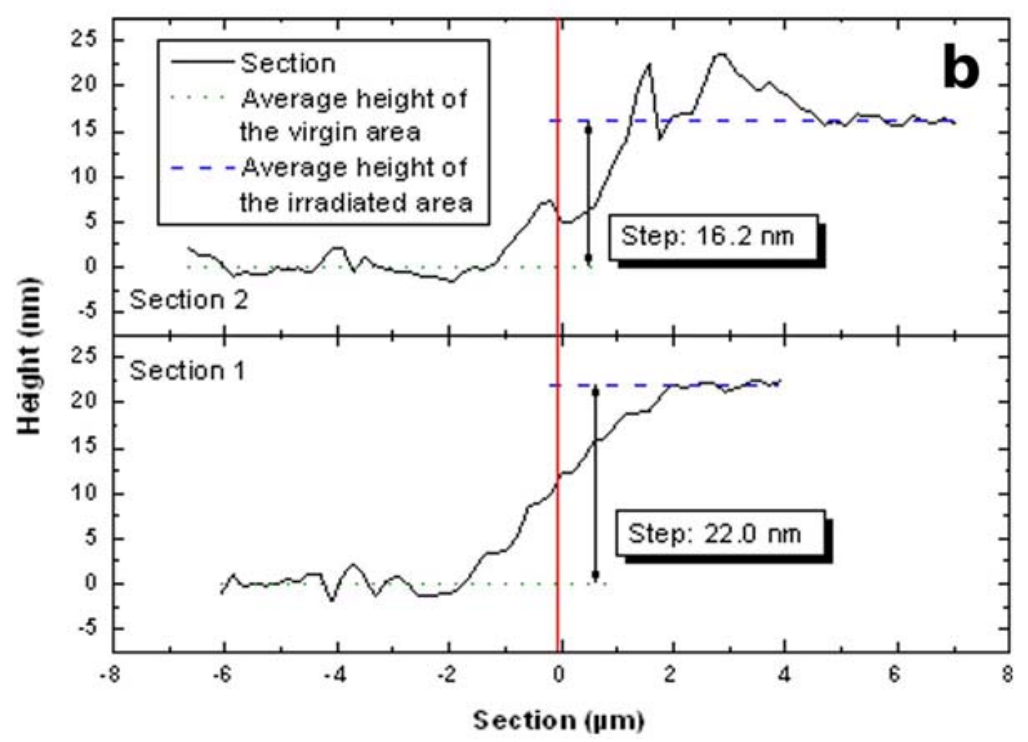

Figure 6: Swelling induced by room temperature irradiation to $10^{19} \mathrm{~m}^{-2}$ : (a) AFM micrograph of the interface between the irradiated and the virgin areas, and (b) profiles of the sections indicated in (a).

It was not possible to obtain micrographs similar to that of Figure 6 for other irradiation conditions (lower fluence and/or higher temperature). Actually, the height difference between virgin and irradiated areas was not sufficient to be observed by optical microscopy. Therefore, it was not possible to position the AFM tip at the interface between virgin and irradiated areas. Nevertheless, observations of the irradiated areas were carried out for other irradiation conditions. Figure 7 presents typical microstructures of irradiated samples as a function of both the fluence (or number of dpa) and temperature. The dark areas on the micrograph recorded on a sample irradiated at room temperature to $10^{17} \mathrm{~m}^{-2}$ are due to porosity. This porosity was also visible before irradiation for this sample. They are certainly due to the pull out of surface grains during the sample preparation. In this Figure, one can also see that the revealing of microstructure 
appears at room temperature between $10^{17}$ and $10^{18} \mathrm{~m}^{-2}$. When the irradiation temperature is raised to $773 \mathrm{~K}$, it appears between $10^{18}$ and $10^{19} \mathrm{~m}^{-2}$. Eventually, no microstructure revealing is noticeable at $1223 \mathrm{~K}$ for a fluence of $10^{19} \mathrm{~m}^{-2}$. Therefore, the formation of this microstructure is enhanced when the fluence is increased, or when the temperature is decreased.

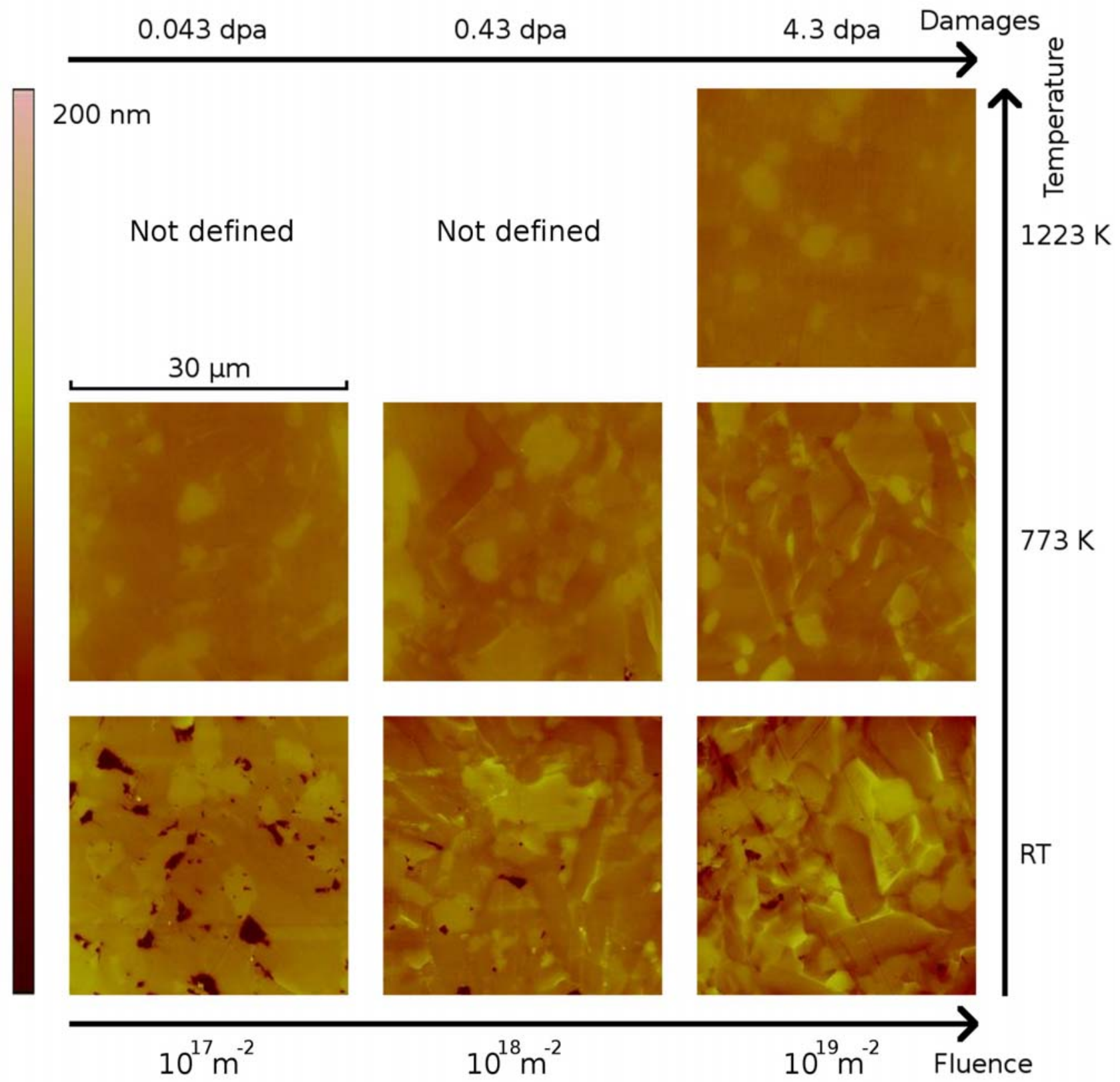

Figure 7: Evolution of the microstructure of irradiated areas as a function of both the temperature and the fluence; RT stands for "room temperature".

\subsection{Origin of the microstructure revealing}

In a previous paper, we attributed the modification of the microstructure induced by irradiation to an effect of sputtering [15]. However, the sputtering yield does not depend on the irradiation temperature, whereas the present results have shown that the microstructure revealing does depend on it. Therefore, invoking sputtering as a possible cause for the microstructure revealing was a misinterpretation of previous data.

The swelling measurements suggest a new and more relevant explanation of this phenomenon. Actually, upon irradiation at room temperature to $10^{19} \mathrm{~m}^{-2}, \mathrm{Ti}_{3} \mathrm{SiC}_{2}$ slightly swells. However, Figure 6 indicates that this swelling is not 
the same for all crystallites, inducing a large difference between the measured heights. So, it is likely that anisotropic swelling occurs, owing to the hexagonal close-packed structure of $\mathrm{Ti}_{3} \mathrm{SiC}_{2}$. Such an anisotropic swelling has already been observed in other materials presenting anisotropic structures [31,35,36]. Moreover, it has been shown that anisotropic swelling leads to the occurrence of significant stresses in the irradiated area, inducing fractures or microcracks at grain boundaries in polycrystalline materials [31,36]. Therefore, the anisotropic swelling would also explain what we previously thought to be an erosion phenomenon of the $\mathrm{Ti}_{3} \mathrm{SiC}_{2}$ grain boundaries [15]: as shown in Figure 8, mircocraks formed in the the grain boundaries of $\mathrm{Ti}_{3} \mathrm{SiC}_{2}$ irradiated at room temperature to $10^{19} \mathrm{~m}^{-2}$.

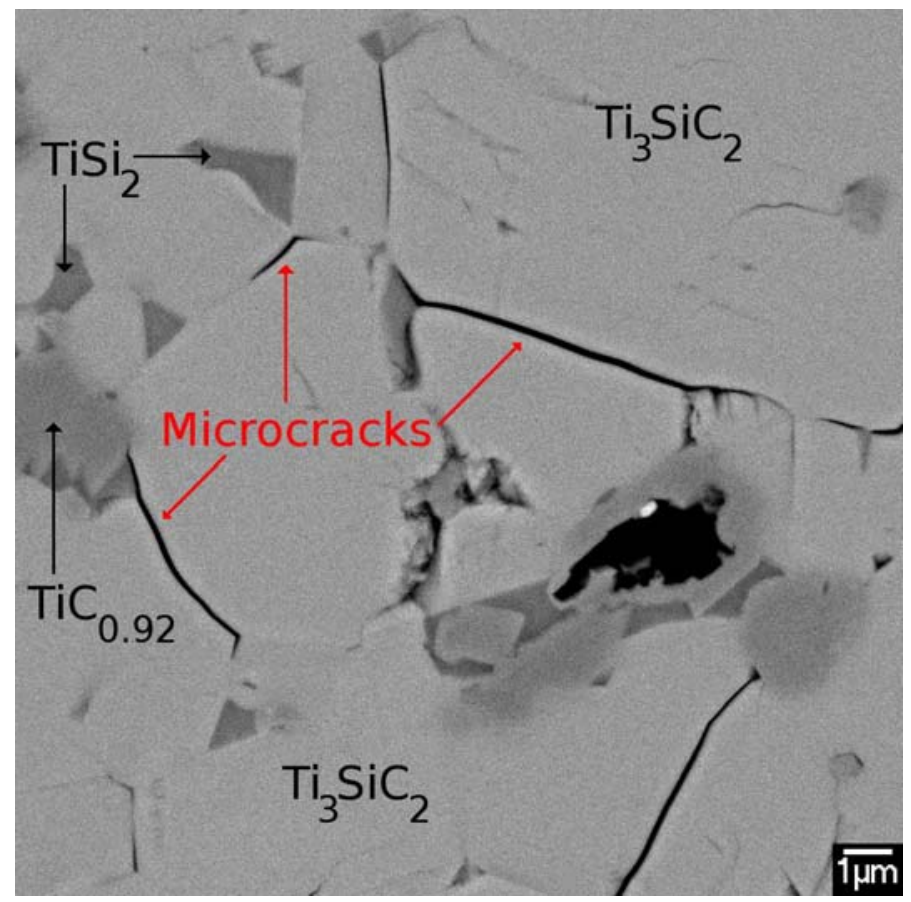

Figure 8: Back-scattered electrons micrograph of the microcrack formation on a sample irradiated at room temperature to $10^{19} \mathrm{~m}^{-2}$.

In this work, where other irradiation conditions were explored, microcrack formation was not observed in other samples. This result confirms the hypothesis that both the formation of microcracks and the microstructure revealing are due to anisotropic swelling of $\mathrm{Ti}_{3} \mathrm{SiC}_{2}$, and that, in the conditions investigated, the swelling of $\mathrm{Ti}_{3} \mathrm{SiC}_{2}$ decreases with decreasing ion fluence and/or with increasing irradiation temperature.

\section{4. $\mathrm{Ti}_{3} \mathrm{SiC}_{2}$ swelling model}

Several authors have discriminated different regimes of swelling in ceramics, which depend on the irradiation temperature [31,32]. At low temperatures, irradiation creates point defects or defect clusters, which lead to the amorphization of the material at high fluence. Defect creation induces a swelling, which increases with increasing fluence, and saturates when amorphization is completed (“amorphization regime"). Above the "critical amorphization temperature $T_{c}$ ", temperature at which the damage recovery rate is equal to the damage rate, amorphization of the material does not occur, even at very high fluences. The value of $T_{c}$ varies as a function of the nature of the material: for instance, $200 \mathrm{~K}$ for graphite [37], 200-250 $\mathrm{K}$ for $\mathrm{Al}_{2} \mathrm{O}_{3}$ [27], 400-650 $\mathrm{K}$ for SiC [38,39]. Thus, above $\mathrm{T}_{c}$, the swelling increases with increasing fluence up to saturation, but it is only due to defect creation ("saturatable regime"). As the material does not become amorphous, the saturation swelling is much smaller than that measured in the amorphization regime, and it steadily decreases with increasing temperature. This decrease is generally attributed to the recombination of Frenkel pairs created in the collision cascades, which is enhanced at high temperature. Eventually, for temperatures high enough to allow vacancies to be significantly mobile, vacancy clusters can form and grow in cavities (or voids). In this "non-saturatable regime", extended defects are the major cause of swelling, which becomes fluence dependent, and increases with increasing temperature. If $\mathrm{Ti}_{3} \mathrm{SiC}_{2}$ follows this model of swelling, it should be in the saturatable regime, whatever the irradiation temperature is. This assumption stems from the following statements: 
(i) Nuclear collisions create defects in $\mathrm{Ti}_{3} \mathrm{SiC}_{2}$ without leading to amorphization [11,12,15], even for the highest studied dose (4.3 dpa), whereas $\mathrm{SiC}$, which is in the amorphization regime at room temperature, becomes amorphous above $0.5 \mathrm{dpa}$. This suggests that $\mathrm{Ti}_{3} \mathrm{SiC}_{2}$ is not in the amorphization swelling regime;

(ii) No extended defects have been observed by transmission electron microscopy analyzes [8], even for the highest temperature (1223 K), suggesting that $\mathrm{Ti}_{3} \mathrm{SiC}_{2}$ is not in the non-saturatable regime;

(iii) The swelling decreases and increases respectively with the temperature and the dose (see Section 3.2.). This behavior is typical of the saturatable regime.

Therefore, the critical amorphization temperature of $\mathrm{Ti}_{3} \mathrm{SiC}_{2}$ would certainly be lower than room temperature, and the transition temperature between the saturatable and the non-saturatable regimes would be higher than $1223 \mathrm{~K}$.

However, as $\mathrm{Ti}_{3} \mathrm{SiC}_{2}$ possesses some properties generally attributed to metals, and has also a behavior under electronic excitations similar to that of metals [8], it could follow another model. According to the literature, metals do not seem to become amorphous for very high dose [40,41], in the temperature range studied in this work. Moreover, the swelling of metals does not saturate, but increases linearly with the dose due to the agglomeration of point defects into extended defects, whatever the irradiation temperature. Eventually, a temperature increase usually induces an increase of the swelling up to a maximum for a critical temperature above which the swelling decreases [42]. Thus, considering that such a critical temperature is ever reached for irradiations at room temperature, the results presented in this work also match with this model, and complementary irradiations, such as irradiations at lower and higher temperatures, or creating more damage, are needed to better understand the swelling behavior of $\mathrm{Ti}_{3} \mathrm{SiC}_{2}$.

\section{Conclusion}

The first aim of this study was to confirm that the microstructure revealing, observed on $\mathrm{Ti}_{3} \mathrm{SiC}_{2}$ irradiated at room temperature with $4 \mathrm{MeV}$ Au ions to $10^{19} \mathrm{~m}^{-2}$, depends on the crystallite orientation. This result was confirmed by combining AFM and EBSD observations that show similarities in the shape and size of both the revealed grains and the crystallites of the samples. Moreover, EBSD analyzes allowed the highlighting a hitherto unexpected result: the secondary phase $\mathrm{TiSi}_{2}$, present in the studied specimen, is highly textured. We conjecture that the formation of a liquid phase during the sample preparation could be the cause of this strong texturing.

The second goal of this work was to develop a methodology to estimate by AFM the volume swelling induced by ion irradiation. The method was validated with measurements performed on an irradiated SiC sample that match the result found in the literature. Using this method, we showed that $\mathrm{Ti}_{3} \mathrm{SiC}_{2}$ weakly swells at room temperature $(2.2 \pm 0.8 \%)$ for an average irradiation dose of $4.3 \mathrm{dpa}$, whereas the swelling of $\mathrm{SiC}$ irradiated in the same conditions reaches $16.4 \%$. Furthermore, we showed that, in the temperature and damage range of our study, the higher the temperature or the lower the amount of damage, the lower the swelling of $\mathrm{Ti}_{3} \mathrm{SiC}_{2}$. However, complementary irradiations are needed to determine the swelling model applicable to $\mathrm{Ti}_{3} \mathrm{SiC}_{2}$, which can be either that implemented for ceramics or that implemented for metals.

Finally, by comparing the micrographs obtained by using both AFM and FEG-SEM, we showed that the microstructure revealing induced by irradiation is due to an anisotropic swelling of $\mathrm{Ti}_{3} \mathrm{SiC}_{2}$. Nevertheless, since neither microstructure revealing, nor crack formation have been observed on the sample irradiated at $1223 \mathrm{~K}$ to $10^{19} \mathrm{~m}^{-2}$, we can conclude that, from the swelling point of view, $\mathrm{Ti}_{3} \mathrm{SiC}_{2}$ seems to present interesting prospects for use as a cladd component of GFR.

\section{Acknowledgement}

The authors would like to greatly thank Isabelle Monnet from CIMAP (Caen, France) for numerous discussions about the swelling of irradiated materials. This work was partly funded by the French research group MATINEX. 


\section{References}

[1] US.DoE, <http://nuclear.energy.gov/genIV/neGenIV1.html>.

[2] J.J. Nickl, K.K. Schweitzer, P. Luxenberg, Gasphasenabscheidung im Systeme Ti-C-Si, J. Less-Common Metals 26 (1972) 335-353.

[3] T. Goto, T. Hirai, Chemically vapor-deposited Ti3SiC2, Mater. Res. Bull. 22 (1987) 1195-1201.

[4] M.W. Barsoum, The M(n+1)AX(n) phases: A new class of solids; Thermodynamically stable nanolaminates, Prog. Solid State Chem. 28 (2000) 201-281.

[5] M.W. Barsoum, T. El-Raghy, The MAX phases: Unique new carbide and nitride materials - Ternary ceramics turn out to be surprisingly soft and machinable, yet also heat-tolerant, strong and lightweight, Am. Scientist 89 (2001) 334-343.

[6] H.B. Zhang, Y.W. Bao, Y.C. Zhou, Current Status in Layered Ternary Carbide Ti3SiC2, a Review, J. Mater. Sci. Technol. 25 (2009) 1-38.

[7] M.W. Barsoum, T. El-Raghy, Synthesis and characterization of a remarkable ceramic: Ti3SiC2, J. Am. Ceram. Soc. 79 (1996) 1953-1956.

[8] J.C. Nappé, I. Monnet, Ph. Grosseau, F. Audubert, B. Guilhot, M. Beauvy, L. Thomé, M. Benabdesselam, Structural changes induced by heavy ion irradiation in titanium silicon carbide, Accepted for Publication in Journal of Nuclear Materials.

[9] J.C. Nappé, I. Monnet, Ph. Grosseau, F. Audubert, B. Guilhot, M. Beauvy, M. Benabdesselam, Hill formation on titanium silicon carbide surface irradiated with swift heavy ions, Under Review.

[10] K.R. Whittle, M.G. Blackford, R.D. Aughterson, S. Moricca, G.R. Lumpkin, D.P. Riley, N.J. Zaluzec, Radiation tolerance of Mn+1AXn phases, Ti3AlC2 and Ti3SiC2, Acta Mater. 58 (2010) 4362-4368.

[11] M. Le Flem, X. Liu, S. Doriot, T. Cozzika, I. Monnet, Irradiation damage in Ti3(Si,Al)C2: a TEM investigation, Int. J. Appl. Ceram. Technol. 7 (2010) 766-775.

[12] X. Liu, M. Le Flem, J.L. Béchade, F. Onimus, T. Cozzika, I. Monnet, XRD investigation of ion irradiated Ti3Si0.90Al0.10C2, Nucl. Instrum. Methods Phys. Res. Sect. B: Beam Interact. Mater. Atoms 268 (2010) 506-512.

[13] M. Le Flem, X. Liu, S. Doriot, T. Cozzika, F. Onimus, J.L. Bechade, I. Monnet, Y. Zhou, Ti3(Si,Al)C2 for nuclear application: Investigation of irradiation effects induced by charged particles, Mechanical Properties and Performance of Engineering Ceramics and Composites IV, 30, Hoboken, NJ, USA, D. Singh \& W.M. Kriven (2010) 189-198.

[14] X. Liu, M. Le Flem, J.L. Béchade, I. Monnet, Nanoindentation investigation of heavy ion irradiated Ti3(Si,Al)C2, J. Nucl. Mater. 401 (2010) 149-153.

[15] J.C. Nappé, Ph. Grosseau, F. Audubert, B. Guilhot, M. Beauvy, M. Benabdesselam, I. Monnet, Damages induced by heavy ions in titanium silicon carbide: Effects of nuclear and electronic interactions at room temperature, J. Nucl. Mater. 385 (2009) 304-307.

[16] J.C. Nappé, Ph. Grosseau, B. Guilhot, F. Audubert, M. Beauvy, M. Benabdesselam, Heavy ions induced damages in Ti3SiC2: Effect of irradiation temperature, Mechanical Properties and Performance of Engineering Ceramics and Composites IV, 30, Hoboken, NJ, USA, D. Singh \& W.M. Kriven (2010) 199-204.

[17] J.F. Ziegler, <http://www.srim.org/>.

[18] T. El-Raghy, M.W. Barsoum, Processing and mechanical properties of Ti3SiC2: I, reaction path and microstructure evolution, J. Am. Ceram. Soc. 82 (1999) 2849-2854.

[19] H. Li, D. Chen, J. Zhou, J.H. Zhao, L.H. He, Synthesis of Ti3SiC2 by pressureless sintering of the elemental powders in vacuum, Mater. Lett. 58 (2004) 1741-1744.

[20] F. Sato, J.F. Li, R. Watanabe, Reaction synthesis of Ti3SiC2 from mixture of elemental powders, Mater. Trans. 41 (2000) 605-608.

[21] F. Audubert, G. Abrivard, C. Tallaron, Characterizations of Ti3SiC2 as candidate for the structural materials for high temperature reactors, Proceedings of the 30th International Conference and Exposition on Advanced Ceramics and Composites, Cocoa Beach, FL, US, (2006). 
[22] I.J. Shon, H.K. Park, H.C. Kim, J.K. Yoon, K.T. Hong, I.Y Ko, One-step synthesis and densification of nanostructured TiSi2-SiC composite from mechanically activated ( $\mathrm{TiC}+3 \mathrm{Si}$ ) powders by high-frequency-induced heated combustion, Scr. Mater. 56 (2007) 665-668.

[23] J. Morgiel, J. Lis, R. Pampuch, Microstructure of Ti3SiC2-based ceramics, Mater. Lett. 27 (1996) 85-89.

[24] R. Radhakrishnan, J. J. Williams, M. Akinc, Synthesis and high-temperature stability of Ti3SiC2, J. Alloy. Compd. 285 (1999) 85-88.

[25] W.G. Spitzer, G.K. Hubler, T.A. Kennedy, Properties of amorphous silicon produced by ion implantation: Thermal annealing, Nucl. Instrum. Methods Phys. Res. 209-210 (1983) 309-312.

[26] J.S. Custer, M.O. Thompson, D.C. Jacobson, J.M. Poate, S. Roorda, W.C. Sinke, F. Spaepen, Density of amorphous Si, Appl. Phys. Lett. 64 (1994) 437-439.

[27] S.J. Zinkle, G.P. Pells, Microstructure of Al2O3 and MgAl2O4 irradiated at low temperatures, J. Nucl. Mater. 253 (1998) 120-132.

[28] M. Terasawa, T. Mitamura, L. Liu, H. Tsubakino, M. Niibe, Metal surface swelling by heavy charged particle irradiation, Nucl. Instrum. Methods Phys. Res. Sect. B: Beam Interact. Mater. Atoms 193 (2002) 329-335.

[29] F. Harbsmeier, J. Conrad, W. Bolse, Generation and relief of mechanical stresses in ion irradiated SiC and SiO2, Nucl. Instrum. Methods Phys. Res. Sect. B: Beam Interact. Mater. Atoms 137 (1998) 505-510.

[30] M. Beauvy, C. Dalmasso, C. Thiriet-Dodane, D. Simeone, D. Gosset, Damages in ceramics for nuclear waste transmutation by irradiation with swift heavy ions, Nucl. Instrum. Methods Phys. Res. Sect. B: Beam Interact. Mater. Atoms 242 (2006) 557-561.

[31] F.W. Clinard Jr., G.F. Hurley, L.W. Hobbs, Neutron irradiation damage in MgO, Al2O3 and MgAl2O4 ceramics, J. Nucl. Mater. 108-109 (1982) 655-670.

[32] L.L. Snead, T. Nozawa, Y. Katoh, T.S. Byun, S. Kondo, D.A. Petti, Handbook of SiC properties for fuel performance modeling, J. Nucl. Mater. 371 (2007) 329-377.

[33] D. Gosset, M. Dollé, D. Simeone, G. Baldinozzi, L. Thomé, Structural behaviour of nearly stoichiometric ZrC under ion irradiation, Nucl. Instrum. Methods Phys. Res. Sect. B: Beam Interact. Mater. Atoms 266 (2008) 2801-2805. [34] L.L. Snead, S.J. Zinkle, J.C. Hay, M.C. Osborne, Amorphization of SiC under ion and neutron irradiation, Nucl. Instrum. Methods Phys. Res. Sect. B: Beam Interact. Mater. Atoms 141 (1998) 123-132.

[35] D. Gosset, D. Simeone, D. Quirion, Neutron irradiation damage to boron carbide: X-ray diffraction analysis, J. Phys. IV 10 (2000) Pr10-55-63.

[36] T. Yano, T. Iseki, Swelling and microstructure of AlN irradiated in a fast-reactor, J. Nucl. Mater. 203 (1993) 249-

254.

[37] H. Abe, H. Naramoto, A. Iwase, C. Kinoshita, Effect of damage cascades on the irradiation-induced amorphization in graphite, Nucl. Instrum. Methods Phys. Res. Sect. B: Beam Interact. Mater. Atoms 127-128 (1997) 681-684.

[38] A. Heft, E. Wendler, T. Bachmann, E. Glaser, W. Wesch, Defect production and annealing in ion implanted silicon carbide, Mater. Sci. Eng. B: Solid State Mater. Adv. Technol. 29 (1995) 142-146.

[39] W.J. Weber, L.M. Wang, The temperature dependence of ion-beam-induced amorphization in beta-SiC, Nucl. Instrum. Methods Phys. Res. Sect. B: Beam Interact. Mater. Atoms 106 (1995) 298-302.

[40] C. David, B.K. Panigrahi, G. Amarendra, S. Abhaya, S. Balaji, A.K. Balamurugan, K.G.M. Nair, B. Viswanathan, C.S. Sundar, B. Raj, Void swelling in ion irradiated (15Ni-14Cr), Ti-modified stainless steel: A study using positron annihilation and step height measurements, Surf. Coat. Technol. 203 (2009) 2363-2366.

[41] F. A. Garner, D. S. Gelles, H. Takahashi, S. Ohnuki, H. Kinoshita, B. A. Loomis, High swelling rates observed in neutron-irradiated V-Cr and V-Si binary alloys, J. Nucl. Mater. 191-194 (1992) 948-951.

[42] A.F. Rowcliffe, A. Hishinuma, M.L. Grossbeck, S. Jitsukawa, Radiation effects at fusion reactor He : dpa ratios: Overview of US/Japan spectrally tailored experiments, J. Nucl. Mater. 179-181 (1991) 125-129. 